\title{
ANALISIS KINERJA LEMBAGA PENYULUHAN DI KABUPATEN INDRAGIRI HULU
}

\section{PERFORMANCE ANALYSIS OF EXTENSION INSTITUTION IN INDRAGIRI HULU DISTRICT}

\author{
Mely Susanti ${ }^{1}$, Rosnita $^{2}$, Roza Yulida ${ }^{2}$ \\ Agribusiness Department, Agriculture Faculty, University of Riau \\ Melysusanti05@gmail.com/082389345023
}

\begin{abstract}
The aims of this study is to describe and analyze the performance of extention institutions in Indragiri Hulu District. The study was conducted in BP4KKP Indragiri Hulu. The number of samples in this study was 127 people including 6 people from BP4KKP that was taken by using purposive sampling and this technique was also used to determine the four districts selected samples which are representative of the population of the district. Samples of farmers were 98 people which were taken by using slovin formula and 23 extention workers by using census method. Description of extension institution was taken by using descriptive analysis and analysis of extension institution was taken by Summated Likert Scale Rating (SLR). The results of this study showed that The role, functions and duties of the extension field has not been fully implemented It can be seen from there are some programs that are not running, then the background of personnel BP4KKP is not suitable with the placement of job profile. The institution has already referred to the Law No. 16 of 2006 which is polyvalent. The common perception among farmers and extention workers toward the performance of institutions was considered by four indicators, namely: responsiveness, responsibility, accountability and quality of service, they showed the results of the institution's performance was in a high category .The problem faced is the small number of extention workers and the low productivity of rice and prevalence of institutional support.
\end{abstract}

Keywords : Extension Institutional, Performance, Extention Workers, Farmer.

1) Mahasiswa Agribisnis Fakultas Pertanian Universitas Riau

2) Dosen Fakultas Pertanian Universitas Riau 


\section{PENDAHULUAN}

Lembaga

penyuluhan

pertanian mempunyai peran strategis untuk pembangunan pertanian di Indonesia karena mempunyai tugas dan fungsi untuk menyelenggarakan pendidikan non formal bagi petani/nelayan serta tugas utama seorangpenyuluh pertanian adalah mendampingipetani,mengajarkanpen getahuan dan keterampilan tentang usahatani, mendidik petani agar mampu memberdayakan semua potensinya, menyebarkan inovasiinovasi baru kepada petani tentang bagaimana berusahatani dengan baik.

Undang-Undang No. 32

Tahun 2004 tentang pemerintahan daerah dan berlakunya otonomi daerah, maka pada zaman ini paradigma pembangunan pertanian telah bergeser dari pendekatan sentralistik menjadi desentralistik dan pendekatan penyuluhan pertanian bergeser dari pendekatan dipaksa menjadi pendekatan partisipatif dan dipengaruhi oleh berbagai kepentingan. Fungsi penyuluhan pertanian dibeberapa provinsi dilaksanakan oleh dinas atau badan lingkup pertanian, namun penanganannya dilakukan secara parsial dan tidak terkoordinasi, karenamandat untuk menyelenggarakan penyuluhan pertanian tidak diatur dengan tegas oleh peraturan perundang-undangan yang berlaku.

Undang-Undang Republik Indonesia No. 22 Tahun 1999 yang diamandemen dengan UU No. 32 Tahun 2004 tentang Pemerintahan Daerah, Undang-Undang nomor 16 Tahun 2006 tentang Sistem Penyuluhan Pertanian, Perikanan dan Kehutanan Peraturuan Pemerintah No. 41 Tahun 2007 tentang Kelembagaan Daerah, telah mewarnai penyelenggaraan penyuluhan pertanian. Penafsiran yang berbeda-beda terhadap kebijakan publik tersebut, telah merubah pranata dan struktur kelembagaan penyuluhan pertanian serta operasionalisasinya di daerah khususnya di Provinsi Riau (Syabrina, 2009).

Kabupaten Indragiri Hulu salah satu kabupaten di Provinsi Riau yang memiliki lembaga khusus yang menangani penyuluh pertanian yaitu Badan Pelaksana Penyuluhan Pertanian Perikanan Kehutanan dan Ketahanan Pangan (BP4KKP). Penilaian kinerja suatu lembaga pemerintahan dalam penelitian ini dapat dilakukan dengan menggunakan beberapa indikator diantaranya adalah Produktifitas karena konsep produktifitas dapat menggambarkan tingkat efesiensi dan efektifitas pelayanan suatu lembaga pemerintahan kepada masyarakat, suatu lembaga pemerintahan juga bisa dilihat dari penilaian masyarakat mengenai Kuliatas Layanan yang diberikan lembaga tersebut karena semakin bagus penilaian masyarakat tehadap lembaga tersebut maka lembaga ini memiliki orientasi yang baik dimasyarakat. Responsivitas, Responsibilitas dan Akuntabilitas memiliki masing-masing peran dalam penilaian suatu kinerja lembaga pemerintahan, karena Responsivitas berorientasi pada pengembangan program-program pelayanan yang sesuai dengan aspirasi masyarakat, sedangkan Responsibilitas menjelaskan apakah pelaksanaan kegiatan organisasi publik itu dilakukan sesuai dengan prinsip-prinsip administrasi yang benar, dan Akuntabilitas menunjuk pada seberapa besar kebijakan dan 
kegiatan organisasi publik tunduk pada para pejabat publik yang dipilih oleh rakyat.

Perubahan pranata sosial kelembagaan ditingkat kabupaten/kota ini mendorong perlu dilakukan penelitian yang menganalisis penyuluhan pertanian yang berada pada lembaga penyuluhan di Kabupaten Indragiri Hulu. Penelitian ini bertujuan untuk mendeskripsikan kelembagaan penyuluhan di Kabupaten Indragiri Hulu. Dan menganalisis kinerja lembaga penyuluhan di Kabupaten Indragiri Hulu.

\section{METODE PENELITIAN Tempat dan Waktu Penelitian}

Penelitian dilaksanakan di Kabupaten Indragiri Hulu karena merupakan salah satu Kabupaten di Provinsi Riau yang memiliki Lembaga penyuluhan yang spesifik menaungi penyuluhan pertanian berdasarkan Undang-Undang No 16 tahun 2006. Lembaga itu dinamakan Badan Pelaksana Penyuluhan Pertanian Perikanan Kehutanan dan Ketahanan Pangan (BP4KKP). Waktu penelitian dimulai bulan Juni sampai dengan November 2016.

\section{Metode Pengambilan Sampel}

Populasi penelitian adalah seluruh pihak yang terlibat dalam kelembagaan penyuluhan pertanian ditingkat kecamatan dan desa di Kabupaten Indragiri Hulu.

Populasi penelitian dari lembaga BP4KKP diwakili dengan 6 (enam) responden sesuai dengan struktur BP4KKP sebagai key informan. Metode pengambilan sampel untuk empat kecamatan dilakukan secara purposive sampling berdasarkan pertimbangan: (1) Jumlah penyuluh terbanyak, (2) Jumlah penyuluh sedikit, (3) Kecamatan dengan jarak terdekat dengan Kota Kabupaten (4) Kecamatan dengan jarak sangat jauh dari Kota Kabupaten. Penentuan sampel jumlah penyuluh menggunakan metode sensus, hal ini karena jumlah sampel yang terlalu kecil, dan untuk menentukan jumlah sampel petani menggunakan rumus Slovin (Umar, 2003 dalam Farlen, 2011). Jumlah responden penyuluh dan petani dapat dilihat pada Tabel 1 .

\section{Tabel 1. Jumlah responden}

\begin{tabular}{lllccc}
\hline No & Kecamatan & \multicolumn{1}{c}{ Desa (Kelompoktani) } & Petani & $\begin{array}{c}\text { Koordinator } \\
\text { Penyuluh }\end{array}$ & Penyuluh \\
\hline 1 & Kuala & 1. Tanjung Sari (Mekar Utama) & 17 & 1 & 6 \\
& Cenaku & 2. Kuala Mulya (Sumber Rezeki II) & 16 & 0 & 0 \\
2 & Peranap & 1. Semelinang Darat (Nusa Indah) & 9 & 1 & 4 \\
& & 2. Sungai Galang (Katipo Pura) & 8 & 0 & 0 \\
3 & Rengat & 1. Alang Kepayang (Mekar Tani) & 12 & 1 & 4 \\
& Barat & 2. Danau Baru (Pantai Indah) & 11 & 0 & 0 \\
4 & Batang & 1. Kota Tuo (Makmur Bersama) & 13 & 1 & 5 \\
& Peranap & 2. Pematang (Melati) & 12 & 0 & 0 \\
\hline
\end{tabular}




\section{Metode Pengumpulan Data}

Data-data yang diperlukan dalam penelitian adalah data primer dan data sekunder, data primer meliputi wawancara dengan penyuluh dan petani yang terkait dengan identitas responden/sampel (umur, tingkat pendidikan, pengalaman kerja, jabatan pekerjaan, masalah dalam berusahatani). Data sekunder yang diperlukan diperoleh dari instansi terkait yang meliputi: Profil BP4KKP Kabupaten Indragiri
Hulu, Struktur Organisasi, tugas pokok dan fungsi BP4KKP Kabupaten Indragiri Hulu, jumlah penyuluh dari setiap Kecamatan di KabupatenIndragiri Hulu, keadaan umum daerah penelitian dan datadata lain yang dianggap perlu dan berkaitan dengan penelitian. Adapun responden (key person) dan panduan wawancara yang akan digunakan dapat kita lihat pada Tabel 2:

Tabel 2. Responden (key person) dan panduan wawancara

\begin{tabular}{|c|c|c|c|}
\hline Tujuan & Key Person & & Panduan Wawancara \\
\hline \multirow[t]{4}{*}{$\begin{array}{l}\text { 1. Menganalisis } \\
\text { kelembagaan penyuluhan }\end{array}$} & $\begin{array}{l}\text { 1. Bidang Kelembagaan dan } \\
\text { Pengembangan SDM }\end{array}$ & & \multirow[t]{4}{*}{$\begin{array}{l}\text { Struktur Lembaga Tugas, } \\
\text { fungsi dan peran }\end{array}$} \\
\hline & $\begin{array}{l}\text { a. SUBBID Kelembagaan dan } \\
\text { Mitra Usaha } \\
\text { b. SUBBID Pengembangan }\end{array}$ & SDM & \\
\hline & $\begin{array}{l}\text { 2. Bidang Penyelenggaraan } \\
\text { Penyuluhan }\end{array}$ & & \\
\hline & $\begin{array}{l}\text { a. SUBBID Pengembangan } \\
\text { Metodologi Penyuluhan } \\
\text { b. SUBBID Pengembangan } \\
\text { Informasi Teknologi } \\
\text { Penyuluhan } \\
\end{array}$ & & \\
\hline
\end{tabular}

Begitu pentingnya penilaian kinerja bagi keberlangsungan organisasi dalam mencapai tujuan, maka perlu adanya indikator pengukuran kinerja yang dipakai secara tepat dalam organisasi tertentu. Menurut Dwiyanto (2006) penilaian kinerja birokrasi publik tidak cukup dilakukan dengan menggunakan indikator yang melekat pada birokrasi itu, seperti efisiensi dan efektivitas, tetapi juga harus dilihat dari indikator-indikator yang melekat pada pengguna jasa, seperti kepuasan pengguna jasa, akuntabilitas dan responsivitas. Penilaian kinerja dari sisi pengguna jasa menjadi sangat penting karena birokrasi publik juga muncul karena tujuan dan misi birokrasi publik sering kali bukan hanya memiliki stakeholder yang banyak dan memiliki kepentingan yang sering berbenturan satu sama lainnya menyebabkan birokrasi publik mengalami kesulitan untuk merumuskan misi yang jelas. Akibatnya ukuran kinerja organisasi publik di mata para stakeholder juga berbeda-beda.

Kinerja BP4KKP di Kabupaten Indragiri Hulu dapat diidentifikasikan melalui berbagai indikator kinerja yang mana hal ini dapat menjadi tolak ukur keberhasilan dalam mengetahui bagaimana kinerja BP4KKP di Kabupaten Indragiri Hulu maka digunakan empat indikator sebagai 
indikasi untuk menilai kinerja yaitu responsivitas, responsibilitas, akuntabilitas dan kualitas layanan. Keempat indikator ini dipilih dengan alasan bahwa indikator ini dirasa telah cukup mewakili dari beberapa indikator yang banyak digunakan untuk menilai kinerja suatu organisasi publik (Budiharsa, 2009). Mengacu pada beberapa pendapat tokoh mengenai indikator kinerja organisasi publik indikator responsivitas, responsibilitas, akuntabilitas dan kualitas layanan ini yang banyak disebutkan untuk menilai kinerja organisasi.indikator dan sub indikator yang digunakan untuk menilai kinerja lembaga penyuluhan di Kabupaten Indragiri Hulu disajikan pada Tabel 3 berikut:

Tabel 3.Indikator penilaian kinerja lembaga penyuluhan

\begin{tabular}{llll}
\hline No & Indikator & & \multicolumn{1}{c}{ Sub Indikator } \\
\hline $\mathbf{1}$ & Responsivitas & $\bullet$ & Mengenali kebutuhan petani \\
& & $\bullet$ & Menentukan prioritas pelayanan \\
& & $\bullet$ & Pengembanganprogram penyuluhan yang Sesuai \\
\hline $\mathbf{2}$ & Responsibilitas & $\bullet$ & Misi dan tujuan penyuluhan pertanian \\
& & $\bullet$ & Program pembangunan pertanian \\
\hline $\mathbf{3}$ & Akuntabilitas & $\bullet$ & Kebijakan lembaga penyuluhan \\
\hline $\mathbf{4}$ & Kualitas Layanan & - Pelayanan,informasi dan penyuluhan \\
& & - Kecepatan dalam memberikan pelayanan \\
& & - Ketepatanmateri dan teknik pelayanan informasi \\
\hline
\end{tabular}

Sumber: Dwiyanto,2006

\section{Analisis Data}

Analisis data yang digunakan penulis dalam penelitian ini adalah analisis deskriptif, analisis kualitatif dan Skala Likert's Summated Rating (SLR) yang masing-masingnya diuraikan sebagai berikut (1) Analisis deskriptif dalam penelitian ini untuk mendeskripsikan kelembagaan penyuluhan di Kabupaten Indragiri Hulu, analisis deskriptif yaitu suatu metode atau cara menganalisa dan menguraikan data-data penelitian yang ada, dan dikaitkan dengan teori-teori yang ada hubungannya dengan permasalahan guna menarik suatu kesimpulan yang disajikan. (2) Analisis Kualitatif dan Skala Likert's Summated Rating (SLR) untuk menganalisis kinerja lembaga penyuluh di Kabupaten Indragiri Hulu.
Skala Likert's Summated Rating (SLR) adalah skala yang digunakan untuk mengukur sikap, pendapat, dan persepsi seorang atau sekelompok orang tentang fenomena sosial. Dalam penelitian, fenomena sosial ini ditetapkan secara spesifik oleh peneliti yang selanjutnya disebut sebagai indikator penelitian (Sugiyono,2011).

Setiap pertanyaan dari indikator yang diberi nilai skala yang berkisar 1 sampai dengan 5. Skala nilai jawaban responden diurut dari nilai yang sangat rendah hingga yang sangat tinggi dengan kriteria sebagai berikut: 
Tabel 4. Kriteria penilaian kinerja lembaga BP4KKP dalam SLR

\begin{tabular}{lc}
\hline $\begin{array}{c}\text { Persetujuan Terhadap } \\
\text { Pernyataan }\end{array}$ & Skala Nilai \\
\hline \multicolumn{1}{c}{1} & 2 \\
\hline Sangat Tinggi (ST) & 5 \\
Tinggi (T) & 4 \\
Cukup Rendah (CR) & 3 \\
Rendah(R) & 2 \\
Sangat Rendah (SR) & 1 \\
\hline \multicolumn{3}{l}{ Sumber: Sugiyono,2011 Dari total nilai pokok-pokok } \\
skala tersebut dikelompokkan \\
menjadi 5 kategori kemampuan \\
kelembagaan penyuluhan pertanian. \\
Tingkatan untuk \\
kelembagaan penyuluhan pertanian \\
dapat di hitung menggunakan rumus \\
yaitu:
\end{tabular}

Rentang Skala $=\frac{5-1}{5}-0,01=0,79$

Berdasarkan kisaran diatas, maka tingkatan untuk menilai kinerja kelembagaan penyuluhan di Kabupaten Indragiri Hulu secara keseluruhan mengenai tingkat kemampuan di bagi 5 yaitu:

Tabel 5. Kategori penilaian kinerja kelembagaan penyuluhan pertanian BP4KKP

Skor Persepsi Petani Sampel

\begin{tabular}{lc}
\hline \multicolumn{1}{c}{ Kategori } & Skor \\
\hline Sangat Tinggi & $4,20-5,00$ \\
Tinggi & $3,40-4,19$ \\
Cukup Tinggi & $2,60-3,39$ \\
Rendah & $1,80-2,59$ \\
Sangat & $1,00-1,79$ \\
Rendah & \\
\hline
\end{tabular}

Sumber: Sugiyono,2011

\section{HASIL DAN PEMBAHASAN}

Badan Pelaksana Penyuluhan Pertanian Perikanan Kehutanan dan
Ketahanan Pangan dibentuk berdasarkan Peraturan Daerah Kabupaten Indragiri Hulu Nomor 3 Tahun 2010 tentang Perubahan Atas Peraturan Daerah Kabupaten Indragiri Hulu Nomor 18 Tahun 2008 tentang Organisasi Perangkat Daerah Pemerintah Kabupaten Indragiri Hulu. Memiliki Tugas Pokok melaksanakan kewenangan Otonomi Daerah dalam rangka tugas Desentralisasi dan Pembantuan di BP4KKP.Kantor BP4KKP bertempat di Jl. Raya Pematang Reba/Puncak Selasih, BP4KKP memiliki kantor perwakilan di setiap kecamatan yang disebut Balai Penyuluhan Pertanian Perikanan Kehutanan dan Ketahanan Pangan.

\section{Struktur BP4KKP}

Berdasarkan Peraturan Daerah Kabupaten Indragiri Hulu Nomor 18 Tahun 2008 tentang Susunan Organisasi Perangkat Daerah Pemerintah Kabupaten Indragiri Hulu menetapkan struktur organisasi BP4KKP Kabupaten Indragiri Hulu dapat dilihat pada Gambar 1.

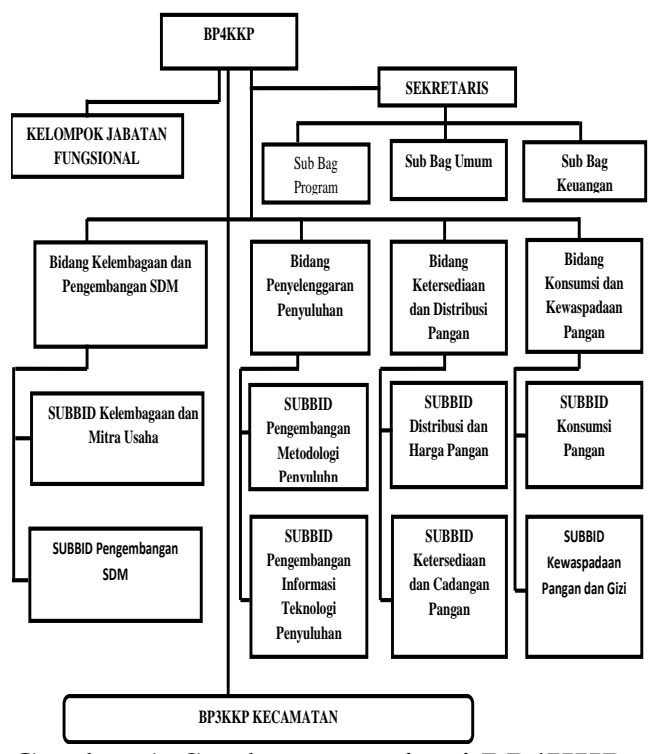

Gambar 1. Struktur organisasi BP4KKP 
Gambar 1 memperlihatkan BP4KKP dikepalai oleh 1 (satu) Kepala Badan, 1 (satu) orang Sekretaris Badan, 4 (empat) orang Kepala Bidang, 3 (tiga) orang Kepala Sub Bagian, dan 8 (delapan) orang Kepala Sub Bidang serta 1 (satu) orang koordinator kelompok jabatan fungsional dan membawahi 14 BP3KKP kecamatan. Struktur organisasi BP4KKP memperlihatkan bahwa tidak seluruh pegawai yang ada dalam struktur organisasi memiliki bidangJu perkebunan dan pertanian. Bahkan ada yang berlatar belakang pendidikan teknik seperti kepala badan, bidang pengembangan informasi teknologi penyuluhan, bidang ketersediaan dan distribusi pangan serta bidang kewaspadaan pangan dan gizi yang berlatar belakang pendidikan social, dan bidang konsumsi dan kewaspadaan pangan yang berlatang belakang pendidikan sarjana pendidikan. Dengan latar belakang pendidikan yang tidak sesuai diduga akan sulit mengembangkan diri dan mengelola kelembagaan dengan baik. Struktur Organisasi BP4KKP Kabupaten Indragiri Hulu menggambarkan bahwa BP4KKP di Kabupaten Indragiri Hulu membawahi 14 BP3KKP Kecamatan.

BP3KKP berada disetiap kecamatan di Kabupaten Indragiri Hulu.SetiapBP3KKP dikepalai oleh seorang kepala yang disebut dengan Kepala BP3KKP yang memiliki tugas dalam mengkoordinir kegiatan penyuluhan di kecamatan agar kegiatan penyuluhan dapat berjalan dengan baik.Kepala BP3KKP merupakan perpanjangan tangan dari Kepala Badan.

Tabel 6.Jumlah penyuluh pertanian kecamatan di Kabupaten Indragiri Hulu

\begin{tabular}{|c|c|c|c|c|}
\hline No & Lembaga & PNS & THL-TBPP & Jumlah \\
\hline 1 & BP3KKP Kuala Cenaku & 2 & 5 & 7 \\
\hline 2 & BP3KKP Rengat & 3 & 2 & 5 \\
\hline 3 & BP3KKP Rengat Barat & 3 & 3 & 6 \\
\hline 4 & BP3KKP Rakit Kulim & 1 & 4 & 5 \\
\hline 5 & BP3KKP Peranap & 3 & 2 & 5 \\
\hline 6 & BP3KKP Seberida & 3 & 4 & 7 \\
\hline 7 & BP3KKP Lubuk Batu Jaya & 2 & 3 & 5 \\
\hline 8 & BP3KKP Kelayang & 2 & 3 & 5 \\
\hline 9 & BP3KKP Batang Gangsal & 4 & 1 & 5 \\
\hline 10 & BP3KKP Batang Cenaku & 4 & 2 & 6 \\
\hline 11 & BP3KKP Sei Lala & 2 & 3 & 5 \\
\hline 12 & BP3KKP Lirik & 2 & 3 & 5 \\
\hline 13 & BP3KKP Pasir Penyu & 4 & 1 & 5 \\
\hline 14 & BP3KKP Batang Peranap & 1 & 5 & 6 \\
\hline & Jumlah & 36 & 41 & 77 orang \\
\hline
\end{tabular}

Sumber : Profil BP3KKP Kecamatan, 2016

Tabel 6 menyajikan BP4KKP di Kabupaten Indragiri Hulu memiliki 84 penyuluh diantaranya empat penyuluh kabupaten, tiga penyuluh kehutanan yang menaungi 
14 kecamatan dan 77 orang penyuluh kecamatan.

Dalam penelitian ini cakupan bahasan untuk mendeskripsikan kelembagaan penyuluhan hanya membahas peran, tugas pokok dan fungsi bidang kelembagaan dan pengembangan SDM serta sub bidangnya dan bidang penyelenggaraan penyuluh serta yang berkaitan dengan bidang penyuluhan.

\section{Bidang Kelembagaan dan Pengembangan SDM}

Bidang kelembagaan dan pengembangan sumber daya manusia dipimpin oleh seorang kepala bidang yang memiliki tanggungjawab kepada kepala badan serta mempunyai tugas membantu kepala badan dalam kelembagaan mitra usaha, dan pengembangan sumber daya manusia. Untuk melaksanakan tugas pokok bidang kelembagaan dan pengembangan sumber daya manusia mempunyai fungsi yaitu; perencanaan program kerja, pengkoordinasian pelaksana tugas, perumusan petunjuk pelaksana, penyiapan bahan-bahan penyusunan rancangan rencana, pengkoordinasian rumusan kebijakan teknis perencanaan, penyusunan laporan bidang, pengkoordinasiaan penyiapan bahan rencana pengembangan pembangunan bidang kelembagaan dan pengembangan sumber daya manusia dan pelaksanaan tugas yang diberikan oleh pimpinan sesuai dengan tugas dan fungsinya.

$$
\text { Sejauh ini kepala bidang }
$$

sudah melaksanakan tugas sebagaimana mestinya yang dimana kepala bidang sudah menyusun programa penyuluhan untuk setiap tahun sesuai dengan kebutuhan petani.

Pengkoordinasian pelaksanaan tugas dan teknis perencanaan, penyusunan laporan dan pelaksanaan tugas lain yang diberikan oleh pimpinan sesuai dengan tugas dan fungsinya. Hal ini dilihat dari BP4KKP sudah sesuai dengan UU No. 16 Tahun 2006 yaitu kelembagaan penyuluhan kabupaten sudah berbentuk badan pelaksana penyuluhan yang dimana semua penyuluhan pertanian, perikanan dan kehutanan sudah berada pada lembaga tersebut atau bersifat polivalen dan Kabupaten Indragiri Hulu sudah melaksanakan peraturan perundang-undangan. Kepala bidang kelembagaan dan pengembangan sumber daya manusia dibantu oleh dua sub bidang diantaranya sub bidang kelembagaan dan mitra usaha dan sub bidang pengembangan sumber daya manusia.

\section{Sub Bidang Kelembagaan dan Mitra Usaha}

Sub bidang kelembagaan dan mitra usaha sudah melaksanakan tugas dalam membantu kepala bidang kelembagaan dan pengembangan sumber daya manusia dalam melakukan pengumpulan data informasi, yang kemudian data tersebut dimuat dalam programa penyuluhan. Sementara itu Sub bidang kelembagaan dan mitra usaha juga sudah melakukan kegiatan dan program seperti mewujudkan kelembagaan petani sebagai wadah untuk mewujudkan kesejahteraan agar meningkatnya kapasitas kemampuan lembaga petani.

\section{Sub Bidang Pengembangan Sumber Daya Manusia}

Sub bidang pengembangan sumber daya manusia dibantu oleh satu orang tenaga honor untuk 
membantu melaksanakan tugas sub bidang. Subbid pengembangan sumber daya manusia sudah melaksanakan tugas dalam membantu kepala bidang kelembagaan dan sumber daya manusia. Dalam melaksanakan identifikasi kebutuhan petani, pengembangan mekanisme, melaksanakan pengumpulan dan pengolahan, penyebaran materi penyuluhan bagi pelaku utama dan pelaku usaha disetiap kecamatan. Seperti program peningkatan kesejahteraan petani dengan melakukan pelatihan petani dan pelaku agribisnis dan program peningkatan penerapan teknologi pertanian/perkebunan melalui cara melakukan pelatihan dan bimbingan pengoperasian teknologi pertanian/perkebunan tepat guna.

\section{Bidang Penyuluhan \\ Penyelenggaraan}

Bidang penyelenggaraan penyuluhan merupakan kedudukan dibawah badan pelaksana. Bidang penyelenggaraan penyuluhan dipimpin oleh seorang kepala bidang dan bertanggungjawab kepada kepala badan. Untuk melaksanakan tugas pokok di bidang penyelenggaraan penyuluhan mempunyai fungsi yaitu; perencanaan program kerja bidang penyelenggaraan penyuluhan, perumusan petunjuk teknis pelaksanaan tugas bidang penyelenggaraan penyuluhan, pengkoordinasian pengelolaan pelaksanaan tugas bidang penyelenggaraan penyuluhan, pengendalian pelaksanaan tugas bidang penyelenggaran penyuluhan, penyusunan laporan bidang penyelenggaraan penyuluhan, pelaksanaan tugas-tugas lain yang diberikan oleh kepala badan.
Pengawasan penyuluh sudah dilakukan, dengan hasil yang didapat pada Tahun 2016 bahwa jumlah penyuluh sebanyak 84 orang yang terdiri dari 43 penyuluh PNS dan 41 orang THL yang tidak merata disetiap daerah sehingga kegiatan penyuluhan menjadi tidak efektif. Melihat kondisi tersebut seharusnya kepala bidang harus segera melapor kepada kepala badan agar masalah ini dapat ditindaklanjuti. Kepala bidang penyelenggaraan penyuluhan dibantu oleh dua sub bidang diantaranya sub bidang pengembangan metodologi penyuluhan dan sub bidang pengembangan informasi teknologi penyuluhan.

\section{Sub Bidang Pengembangan Metodologi Penyuluhan}

Sub bidang pengembangan metodologi penyuluhan memiliki satu tenaga honor yang membantu tugas sub bidang pengembangan metodologi penyuluhan dalam membantu kepala bidang. Sub bidang pengembangan metodologi penyuluhan sudah melaksanakan tugas dalam membantu kepala bidang penyelenggaraan penyuluhan dalam pengembangan mekanisme, tata kerja dan metode penyuluhan serta melaksanakan pengumpulan, pengolahan, pengemasan dan penyebaran materi penyuluhan. Diantaranya mewujudkan pelayanan informasi teknologi pertanian untuk mendukung peningkatan produksi dan produktivitas dengan melakukan kegiatan penyuluhan penerapan teknologi pertanian/perkebunan tepat guna.

\section{Sub Bidang Pengembangan informasi Teknologi Penyuluhan Berdasarkan struktur organisasi BP4KKP keberadaan sub}


bidang pengembangan informasi teknologi penyuluhan berada dibawah tanggung jawab dari bidang penyelenggara penyuluh. Dalam menjalankan tugas dan tanggung jawabnya sub bidang pengembangan informasi teknologi penyuluhan dibantu oleh satu orang tenaga honor yang membantu tugas keseharian dari subbid. Berdasrkan kondisi lokasi penelitian tugas dan fungsi subbid pengembangan informasi teknologi penyuluhan sudah terlaksana. Diantaranya dalam hal peningkatan kesejahteraan petani yang dilakukan dengan cara penyuluhan pendampingan petani dan pelaku agribisnis, dan program pemberdayaan penyuluh pertanian/perkebunan lapangan melalui cara peningkatan kapasitas tenaga penyuluh pertanian atau perkebunan.

\section{Program Lembaga Penyuluhan di Kabupaten Indragiri Hulu}

Keberhasilan penyuluhan pertanian dalam membangun perilaku Sumber Daya Manusia (SDM) yang profesional kearah yang baik dapat dilihat dari dinamika para pelakunya baik dari jenis, bentuk, kualitas serta derajat partisipasinya pada setiap aspek kegiatan dalam sistem agribisnis. Penyelenggaraan penyuluhan dapat berhasil dengan baik jika ada alat pedoman yang dapat dijadikan petunjuk dalam melaksanakan kegiatan penyuluhan.Alat pedoman itu dinamakan dengan program penyuluhan.

Adapun program dari bidang kelembagaan dan penyelenggaraan penyuluhan BP4KKP Kabupaten Indragiri Hulu tahun 2015 dapat dilihat pada Tabel 7 .

\section{Tabel 7. Program penyuluhan BP4KKP Tahun 2015}

\begin{tabular}{|c|c|c|c|}
\hline No & Bidang & Program & Realisasi \\
\hline \multirow[t]{4}{*}{1} & $\begin{array}{l}\text { Bidang kelembagaan dan } \\
\text { pengembangan SDM }\end{array}$ & $\begin{array}{l}\text {-Pengoperasian teknologi } \\
\text { pertanian/perkebunan tepat guna }\end{array}$ & Juli \\
\hline & $\begin{array}{l}\text { *Subbid kelembagaan dan } \\
\text { mitra usaha }\end{array}$ & $\begin{array}{l}\text {-Peningkatan kapasitas tenaga } \\
\text { penyuluh pertanian/perkebunan }\end{array}$ & Oktober \\
\hline & *Subbid pengembangan SDM & $\begin{array}{l}\text {-Pelatihan petani dan pelaku } \\
\text { agrobisnis }\end{array}$ & Oktober \\
\hline & & $\begin{array}{l}\text {-Peningkatan kemampuan } \\
\text { lembaga petani }\end{array}$ & September \\
\hline \multirow[t]{5}{*}{2} & $\begin{array}{l}\text { Bidang penyelenggaraan } \\
\text { penyuluhan }\end{array}$ & $\begin{array}{l}\text { - Kegiatan penyuluhan penerapan } \\
\text { teknologi pertanian/perkebunan } \\
\text { tepat guna }\end{array}$ & Mei \\
\hline & *Subbid pengembangan SDM & $\begin{array}{l}\text {-Penyuluhan dan pendampingan } \\
\text { petani dan pelaku agrobisnis }\end{array}$ & $\begin{array}{l}\text { Januari- } \\
\text { Desember }\end{array}$ \\
\hline & $\begin{array}{l}\text { *Subbid pengembangan } \\
\text { informasi teknologi } \\
\text { penyuluhan }\end{array}$ & $\begin{array}{l}\text {-Peningkatan kesejahteraan } \\
\text { tenaga penyuluh } \\
\text { pertanian/perkebunan }\end{array}$ & $\begin{array}{l}\text { Januari- } \\
\text { Desember }\end{array}$ \\
\hline & & $\begin{array}{l}\text {-Penyuluhan dan pendampingan } \\
\text { bagi pertanian/perkebunan }\end{array}$ & Juli \\
\hline & & $\begin{array}{l}\text {-Penyuluhan kesadaran } \\
\text { masyarakat mengenai dampak } \\
\text { perusakan hutan }\end{array}$ & Juni \\
\hline
\end{tabular}

Sumber : Program kegiatan BP4KKP, 2015 
Berdasarkan Tabel 7, bidang kelembagaan dan pegembangan SDM beserta subbidnya memiliki program yang telah terealisasi diantaranya adalah pengoperasian teknologi pertanian/perkebunan tepat guna yang terealisasi pada bulan juli, kegiatan yang ditekankan pada program ini yakni demplot untuk tanaman padi sawah, demplot tanaman sayuran, demplot terassering untuk lahan miring, kaji terap penggemukan sapi dengan pakan limbah sawit. Kemudian program Peningkatan kapasitas tenaga penyuluh pertanian/perkebunan yang dilakukan dengan pelatihan-pelatihan penyuluh pertanian lapangan tentang pengembangan budidaya padi, jagung, kedelai (PAJALE) program ini lebih ditekankan dikarenakan berdasarkan instruksi dari pemerintah yang lebih menekankan pada sektor pertanian khususnya pangan. Untuk programPelatihan petani dan pelaku agrobisnis bidang kelembagaan dan pengembangan SDM dilakukan dengan cara pelatihan-pelatihan yang diberikan lembaga untuk komoditi tanaman padi, jagung dan kedelai, pelatihan ini diberikan kepada 90 kelompoktani dari seluruh kecamatan yang ada di Kabupaten Indragiri Hulu. Kemudian yang terakhir adalah program Peningkatan kemampuan lembaga petani, kegiatannya berupa pekan daerah kontak tani nelayan andalan (PEDA KTNA) ke-15 tingkat Provinsi Riau. Metode yang digunakan dalam penyampaian materi banyak menggunakan metode diskusi, wawancara, kunjungan dan demontrasi plot.

Program yang telah terealisasi dari Bidang penyelenggaraan penyuluhan dan kepala subbidnya berupa program penyuluhan penerapan teknologi pertanian/perkebunan tepat guna yang dilakukan dengan kegiatan demplot kaji terap tanaman padi sawah, jagung, kacang tanah, ubi kayu, dan cabe. Selanjutnya adalah Penyuluhan dan pendampingan petani dan pelaku agrobisnis yang dilaksanakan pada Bulan JanuariDesember dilakukan dengan kegiatan pendampingan kelompoktani pembudidayaan pertanian, perkebunan, perikanan dan peternakan dengan total kelompoktani yang dibina sebanyak 682 kelompoktani. Program Peningkatan kesejahteraan tenaga penyuluh pertanian/perkebunaan yang dilakukan dengan kegiatan berupa pendampingan kelompoktani penerima bantuan dinas instansi tahun berjalan yang ditangani langsung oleh kepala subbid pengembangan informasi teknologi penyuluhan. Program yang terakhir adalah Penyuluhan kesadaran masyarakat mengenai dampak perusakan hutan yang terealisasi pada bulan juni kegiatannya berupa sosialisai bahaya pembakaran lahan dan hutan, hal ini dirasakan sangat penting dikarenakan kejahatan pembakaran lahan secara sengaja dan tidak memperhatikan ekosistem yang ada sangat merugikan bagi semua pihak ditambah lagi untuk Provinsi Riau merupakan salah satu provinsi yang memiliki kasus pembakaran hutan secara sengaja terbanyak.

Dapat dilihat bahwa program yang disusun oleh BP4KKP Kabupaten Indragiri Hulu khususnya bidang kelembagaan dan pengembangan SDM dan bidang penyelenggaraan penyuluhan tidak seluruhnya terlaksana sesuai dengan 
jadwal. Ada beberapa materi yang dilaksanakan lebih cepat dibandingkan dengan jadwal yang telah disusun dan sebaliknya, selain itu masalah klasik yang seringkali terjadi adalah penghapusan anggaran (rasionalisasi), masalah terbenturnya kebijakan pemerintah yang ada juga mempengaruhi terlaksananya program yang dibuat hal ini dikarenakan kurang sesuai dengan wilayah setempat.

\section{Kinerja Kelembagaan Penyuluhan Pertanian}

Kinerja merupakan gambaran mengenai tingkat pencapaian pelaksanaan suatu program kegiatan atau kebijakan dalam mewujudkan sasaran,tujuan,visi dan misi organisasi yang dituangkan melalui perencanaan strategis suatu organisasi. Penilaian organisasi adalah kegiatan membandingkan antara hasil yang diperoleh atau kenyataan. Oleh karena itu, jika tanpa tujuan dan target yang ditetapkan dalam pengkuran, maka kinerja seseorang atau kinerja organisasi tidak mungkin dapat diketahui bila tidak ada tolak ukur keberhasilannya.

Dalam pembahasan ini akan dibahas mengenai kinerja Badan Pelaksana Penyuluhan Pertanian
Perikanan Kehutanan dan Ketahanan Pangan di Kabupaten Indragiri Hulu. Untuk mengukur kinerja kegiatan penyuluhan berdasarkan persepsi penyuluh dan petani menggunakan indikator yang dikemukan oleh Dwiyanto (2006) yakni indikator responsivitas dengan sub indikator mengenali kebutuhan petani, menentukan prioritas pelayanan dan pengembangan program penyuluhan yang sesuai. Indikator responsibilitas yang dinilai dari misi dan tujuan penyuluhan pertanian dan program pembangunan pertanian. Indikator akuntabilitas berdasrkan kebijakan lembaga penyuluhan dan yang terakhir indikator kualitas layanan yang dinilai berdasarkan pelayanan informasi dan penyuluhan, kecepatan dalam memberi pelayanan dan ketepatan materi dan teknik pelayanan informasi..

\section{Persepsi responden terhadap kinerja BP4KKP}

Hasil analisis keempat indikator kinerja yang dinilai penyuluh dan petani yaitu indikator responsivitas, indikator responsibilitas, indikator akuntabilitas dan indikator kualitas layanan memperoleh hasil yang berbeda-beda, untuk lebih jelasnya dapat dilihat pada Tabel 8 berikut:

Tabel 8. Rekapitulasi penilaian kinerja BP4KKP Kabupaten Indragiri Hulu

\begin{tabular}{llcccc}
\hline No & Indikator & Penyuluh & Kategori & Petani & Kategori \\
\hline 1 & Responsivitas & 3,96 & Tinggi & 3,53 & Tinggi \\
2 & Responsibilitas & 3,71 & Tinggi & 3,56 & Tinggi \\
3 & Akuntabilitas & 3,66 & Tinggi & 3,20 & Cukup Tinggi \\
4 & Kualitas Layanan & 3,72 & Tinggi & 3,52 & Tinggi \\
\hline & Rata-rata & 3,76 & Tinggi & 3,45 & Tinggi \\
\hline
\end{tabular}

Kinerja BP4KKP Kabupaten Indragiri Hulu, berdasarkan penilaian penyuluh dan petani tidak terdapat perbedaan yang signifikan. Menurut 
jawaban penyuluh kinerja BP4KKP masuk dalam kategori "Tinggi" dengan skor 3,76, hal ini dikarenakan peran BP4KKP ditengah-tengah petani memberikan kontribusi yang sangat berarti seperti dalam hal pemenuhan kebutuhan petani dalam berusahatani, pemberian bibit unggul, pupuk subsidi, pestisida, teknik-teknik dalam berusahatani yang baik.

Keseriusan BP4KKP dalam membina petani binaannya juga ditunjukan dari rutinnya atau seringnya penyuluh melakukan kunjungan kerja ke setiap petani binaannya, guna menjalankan tugas dari BP4KKP dalam hal pembinaan petani. Melalui pelatihan-pelatihan yang bertujuan meningkatkan kesejahteraan petani, kemudian program-program dan kebijakan yang sesuai dengan keadaan daerah setempat.

Penilaian petani terhadap BP4KKP Kabupaten Indragiri Hulu, mendapatkan skor berdasarkan analisis per indikator kinerja dan sub indikator kinerja maka diperoleh hasil secara keseluruhan berada dalam kategori "Tinggi" dengan skor 3,45 , hasil ini tidak jauh berbeda dengan jawaban dari penyuluh mengenai kinerja lembaga. Kinerja BP4KKP di Kabupaten Indragiri Hulu berdasarkan indikator responsivitas, responsibilitas, akuntabilitas dan kualitas layanan, karena dari analisis per indikator dan sub indikator dari kinerja menunjukkan hasil penilaian pada kategori "Tinggi", hanya indikator akuntabilitas yang berada pada kategori "Cukup tinggi". Menurut sampel petani dalam penelitian ini menilai kinerja lembaga sudah cukup bagus, hal ini terlihat dari pelayananpelayanan yang diberikan lembaga, ketanggapan lembaga dalam melaksanakan kegiatan penyuluhan, program-program dan kebijakan yang dibuat lembaga seperti penggunaan bibit unggul, pengadaan pupuk subsidi, bantuan pestisida. Keseriusan penyuluh melakukan kunjungan rutin dalam peningkatan pengetahuan petani dalam hal berusahatani, pemecahan masalah petani yang dihadapi petani padi dalam berusahatani dan pelatihan-pelatihan lain yang bertujuan meningkatkan kualitas SDM.

Akan tetapi kurang meratanya program yang didapat petani menjadi salah satu kendala petani, kemudian tidak sesuainya bibit yang diberikan lembaga juga turut menambah permasalahan petani. Diantaranya adalah pada Kecamatan Rengat Barat mayoritas masyarakat tidak menyukai beras yang bertekstur pulen, akan tetapi bantuan bibit yang diberikan lembaga kepada petani adalah benih yang bertekstur pulen. Sehingga petani lebih menggunakan bibit sendiri dan kurangnya hasil produktifitas, petani padi lebih cendrung mengkonsumsi hasil produksi sendiri dari pada menjualnya, kemudian dari beberapa sampel kelompoktani yang ada di kecamatan mengalami permasalahan pada buruknya saluran irigasi. Dimana pada kondisi penghujan tanaman padi petani akan tergenang air dan pada saat musim kemarau tanaman padi mengalami krisis air, hal ini jelas berdampak kepada rendahnya produktifitas tanaman padi dari petani. 


\section{KESIMPULAN DAN SARAN}

\section{Kesimpulan}

Berdasarkan hasil penelitian serta pengamatan yang saya lakukan di Kabupaten Indragiri Hulu diperoleh kesimpulan sebagai berikut

1. Peran, fungsi dan tugas pokok dari bidang penyuluhan belum sepenuhnya dilaksanakan dengan baik sesuai dengan aturan kebijakan yang diterapkan, kemudian penempatan jabatan dirasa kurang sesuai dengan latar belakang yang dimiliki personil BP4KKP serta lembaga BP4KKP sudah mengacu pada UU No 16 Tahun 2006 .

2. Kinerja BP4KKP Kabupaten Indragiri Hulu mendapatkan hasil dalam kategori "Tinggi". Berdasarkan variabel responsivitas, responsibilitas, akuntabilitas dan kualitas layanan, baik berdasarkan persepsi penyuluh dan petani dengan nilai skor yang berbeda yakni skor 3,76 menurut penyuluh dan 3,45 menurut petani.

3. Ada beberapa masalah yang masih belum terselesaikan oleh lembaga seperti masalah pemasaran hasil produksi, rendahnya produktivitas padi yang membuat petani lebih memilih mengkonsumsi hasil produksi dari pada menjualnya. Adanya ketidak sesuaian bantuan yang diberikan lembaga seperti jenis bibit yang tidak sesuai dengan keinginan dan kondisi tanah juga menambah permasalahan yang dihadapi petani, tidak meratanya bantuan yang diterima petani dan masalah permodalan masih menjadi kendala yang berarti.

\section{Saran}

1. Penetapan jabatan struktur lebih baik disesuaikan dengan latar belakang pendidikan. Perlunya dilakukan penambahan jumlah penyuluh dan perlu dilakukannya pelatihan peningkatan SDM yang ada dilembaga guna meningkatkan pengetahuan.

2. Sebelum memberikan bantuan perlu disesuaikan dengan kebutuhan petani sehingga benar-benar dapat menyelesaikan permasalahan usahatani yang dihadapi oleh petani padi. Selain itu perlu adanya program yang benar-benar serius dalam hal peningkatan produktifitas petani, bisa berupa bantuan-bantuan saprodi dan bantuan ini sifatnya harus berkelanjutan. Bantuanbantuan permodalan bagi petani padi juga perlu dilakukan agar lahan petani yang seharusnya diperuntukkan untuk komoditi pangan tidak beralih fungsi menjadi lahan perkebunan baik itu karet maupun kelapa sawit.

\section{Daftar Pustaka}

Badan Pelaksana Penyuluh Pertanian, 2015. Data Penyuluh Pertanian Kabupaten Indragiri Hulu.Indragiri Hulu.

2016. Data Penyuluh Pertanian Kabupaten Indragiri Hulu. Indragiri Hulu.

\begin{tabular}{l} 
Budhiarsa Arif, D, 2009.Kinerja \\
kantor pertanahan dalam \\
pelayanan \\
\multicolumn{4}{c}{ sertifikasi } \\
tanah(Studi Deskriptif Atas \\
Pelayanan Sertifikasi Peralihan \\
Hak Atas Tanah di Kantor \\
Pertanahan Kota Surakarta \\
2008- 2009). Surakarta: \\
Universitas Sebelas Maret.
\end{tabular}


Dwiyanto Agus, dkk, 2006. Reformasi birokrasi publik di Indonesia. Yogyakarta: Gadjah Mada University press.

Farlen, Frans. 2011. Pengaruh motivasi kerja dan kemampuan kerja terhadap kinerja karyawan (Studi Pada PT. UnitedTractors, TBK Samarinda.Skripsi Jurusan Administrasi Bisnis Fakultas Ilmu Sosial dan Ilmu Politik Universitas Pembangunan Nasionl "Veteran". Yogyakarta (Dipublikasikan)

Peraturan Daerah Kabupaten Indragiri Hulu. Nomor 18 tahun 2008 tentang Susunan Organisasi Perangkat Daerah Pemerintah Kabupaten Indragiri Hulu.Indragiri Hulu.

Sugiyono.2011 .Statistik Untuk Penelitian.Bandung : Alfabeta.

Syabrina, 2009.Analisis kelembagaan penyuluhan pertanian di Provinsi Riau.Tesis.Institut Pertanian Bogor.

Undang-Undang Republik Indonesia No. 16 Tahun 2006.Sistem Penyuluhan Pertanian, Perikana, dan Kehutanan. Jakarta : Badan Pengembangan SDM Pertanian Departemen Pertanian.

Undang-undang Republik Indonesia No. 32 tahun 2004 tentang Pemerintah Daerah. 